\title{
A Linguistic Analysis of the Politeness Strategies Used in Doctor-Patient Discourse
}

\author{
Muhammad Arfan Lodhi ${ }^{1}$, Farah $\mathrm{Naz}^{2}$, Sumaira Yousaf ${ }^{3} \&$ Syeda Nimra $\mathrm{Ibrar}^{4}$ \\ ${ }^{1}$ Higher Education Department Collegiate Wing, Punjab, Pakistan \\ ${ }^{2}$ Center of Excellence, Daanish School Rojhan, Pakistan \\ ${ }^{3}$ Apex Taxation Pakistan, Pakistan \\ ${ }^{4}$ Government Sadiq College Women University, Bahawalpur, Pakistan \\ Correspondence: Dr. Muhammad Arfan Lodhi, Higher Education Department Collegiate Wing, Punjab, Pakistan. \\ E-mail: samaritan_as@hotmail.com
}

\author{
Received: December 5, 2018 Accepted: December 23, 2018 Online Published: January 28, 2019 \\ doi:10.5539/ells.v9n1p80 URL: https://doi.org/10.5539/ells.v9n1p80
}

\begin{abstract}
Effective and well-organized communication between the doctors and patients plays a fundamental clinical role and results patient's early healing of body and mind. Most of the patients' annoyance and complaints are observed due to the communication gap found in the doctors-patients discourse. This research study was carried out to locate whether divergences occur or not in the utilization and integration of politeness strategies used in medical discourse. The aim of the study is to discover and highlight the communication gap between doctors and patients. In this ethno-linguistic exploratory study, both quantitative and qualitative data were obtained to find answers of the formulated research questions. Findings reveal that majority of the doctors unduly focus on exhibiting power and dominance over patients in their talks made with them. It was also found that doctors mostly use the strategy of 'Bald on Record' with both male and female patients; and wide majority of patients showed dissatisfaction with doctors' conversation during diagnosing, treatment and follow-up visits. It is recommended that doctors should be made liable to execute good politeness and ethical strategies while communicating with patients for medical purposes.
\end{abstract}

Keywords: doctor-patient discourse (DPD), politeness strategies, power and dominance, distance, power and rectification (DPR)

\section{Introduction}

\subsection{Rational of the Study}

Doctor-patient relationship is considered the important and the harmonious relationship regarding its role in the promotion of health care system. Medical professionals are trained to execute polite and humble behavior with their patients. It is inevitable for doctors to show care and concern during diagnosis and treatment of diseases. In Pakistan, majority of the population pays visit to the government hospitals where vast gap of communication is observed between doctors and patients. Due to the over burdened visits of patients the doctors fall victim of unceasing tension and pressure. Doctors cannot cultivate a good communication; rather display inflexibility and present lower levels of politeness in their talks made with patients. The success rate of the patient's treatment after consulting a doctor mainly depends upon the interactional approach between the doctor and the patient.

Language is undoubtedly a unique system of emblematic communication containing the explanation and coding of connotation as well as denotation, which performs different tasks. In this study, the researchers remained anxious and concerned about the communicating role of language. Though, differences in the discourse of individuals along with the variances in the language can lessen the efficiency of communication. Therefore, language, linguistic devices and pragmatic markers used in doctor patient discourse (DPD) affect 'distance, power and rectification' (DPR) to great extent. Not focusing on all possible factors that may affect the quality of doctor-patient communication in, this study assessed only those causes that were considered relevant in affecting the level of politeness in the conversation between the doctors and the patients. The researchers have addressed such factors by using super strategies of politeness (Brown \& Levinson, 1987). 


\subsection{Statement of the Problem}

The endeavors in therapeutics of physician-patients collaboration rest upon how doctors infer and reply to patients' implicit as well as explicit message. So, researchers have attempted to investigate the linguistic and markers used by doctors during interaction. Furthermore, doctors' dominance, power and hegemony are often found most specifically in state-run hospitals. Patients who often belong to poor socio-educational background face lot of communication difficulties and behavioral problems from the doctors in government hospitals. This study attempted to highlight the linguistic barriers confronted by patients and in response the satisfaction level of patients during medical treatment.

\subsection{Research Questions}

1) What kinds of factors influence the doctor-patient communication at government hospitals in Pakistan?

2) To what extent ethical values and politeness strategies are important in the doctor-patient relationship?

3) How and why politeness maxims and conversation implicatures are employed by doctors in doctor-patient discourse (DPD)?

\subsection{Relevant Secondary Data}

The relation and interaction of doctor-patient DPR (Distance, Power, Rectification) is the utmost and essential part of the clinical practice. It has been corroborated by meticulous studies and observations that if doctor and patients are having good communication, it will create valuable outcomes. As soon as a doctor takes the responsibility of treating a patient, a bond develops between them on linguistic, moral and professional grounds. But in Pakistan, for the last several years, the relationship between doctors and patients is suffering from continuous stress especially at government hospitals. If we turn out the pages of history, it will be noted that Parson (1978), the sociologist by profession, was the first one to detect the DPR. Since then DPR has remained under discussion by several critics and investigators. Linguistic devices, pragmatic markers, verbal clues and non-verbal expressions impinge DPR in medical discourse. Furthermore, politeness strategies hold central position in medical discourse, most specifically in DPD.

According to Leech (1983), politeness is the form of a conduct that aims to cultivate and foster up a standard of mutual harmony in discourse. Brown and Levinson (1987) have also presented the same idea that politeness means the conversation that does not leave any bad impression on the listener. By following these notions of politeness, it can clearly be seen that the discourse of doctors is completely void of ethics and graciousness. The communication aptitude of busy doctors and particularly the doctors who execute their duties in government hospitals remain poorly developed, and they are always in dire need of improving their communication skills. Brown \& Yule (1983) convey that we can express politeness in decent ways by showing awareness and consideration for another person's face. The model presented by Brown and Levinson (1978) records five types of super-strategies which reveal how a person selects a politeness approach in order to utilize it in explicit circumstances. This type of specific model confines those politeness strategies which are exercised in any person's communal interface and conversation.

Table 1. Brown and Levinson's (1978) super strategies

\begin{tabular}{l}
\hline Brown and Levinson Model of Super-Strategies \\
\hline Bald-on-record (Performing FTA, without redressive action, on record) \\
Positive politeness (Performing FTA, with redressive action, on record) \\
Negative politeness (Performing FTA, with redressive action, on record) \\
Off-record (Performing FTA) \\
Maximum politeness (Not performing FTA) \\
\hline
\end{tabular}

Brown and Levinson (1987, p. 61) further familiarized the idea of "face" that is the image shown to world that everybody wants to claim. In their context face comprises two interrelated aspects; positive face (yearning to have one's involvement approved of), and negative face (aspiration to express one's concepts deprived of resistance). Meanwhile most speech actions are fundamentally face threatening acts (FTA), face saving acts (FSA), and politeness strategies hired to minimize FTA. Three liberated social aspects govern the stages of politeness

- Coordination or social distance between interlocutors (D).

- Comparative status power variation amongst interlocutors (P). 
- Culture ratifications of the imposition (R).

According to the concept of face threats in the investigative communication between the doctor and the patient in all the countries, the doctor and patients both have to use FTA devoid of redress (bald on record) or negative politeness. The encounter between the doctor and the patient can be explained in a much better way as this meeting is normally held in professional manner and the members involved in this communication must have to identify, point out, locate, and explain fully the issues of the patients related to the health and well-being. The standard of communication in the process of medical consultation is a complicated phenomenon which can be perceived by different perspectives (Frederickson \& Bull, 1995; Cassel \& Skopek, 1977). The medical terminology used by the doctors during their conversation is also a valid source of creating distances between the doctor and the patients. According to the statement of Toronto Consensus, the language used by the doctors is often unclear as regards to the use of jargons and in relation to the lack of expected shared meanings of relatively common terms (Simpson et al., 1991, p. 1385; Hak, 1995, p. 405). It had been proved that patients were unable to understand a large portion of the conversation of their doctors and were unsuccessful in reminding before others what their doctor had prescribed for them.

In clinical practices a well-known and most effective tool is medical discourse which is not given much importance. Medical discourse in the broadest sense has a major role in the process of diagnosing and treating the patients. The discourse between a doctor and the patient is always proved to be fruitful if the doctor pays attention to the patient and listen carefully to what he/she is saying. The personal way and style of the doctor while consulting with his patients affected the satisfaction rate of the patients as well. In view of Korsch (1972) and his colleagues it has been narrated that a large number of patients who thought that their consultants were friendly in their behavior and were very informal with them, their rate of satisfaction was much higher. With reference to the patient and their gender and the way of communication Maynard (1991) have observed that male and female patients are different in their style of interacting with their doctor and also in the way in which they explain their medical problems to their consultants (Maynard, 1991). While explaining their problems to the doctors, women are inclined more towards giving references of their family members, colleagues and friends (Waitzkin \& Britt, 1999, p. 2444).

The social class, status and the education level of the patients also predict of the behavior of doctor towards them (Epstein et al., 1993, p.101). The patients who are more literate get more time and information from the doctor than the patients who are less educated and have never visited the college. Likewise the patients belonging to the superior and elite classes get more time and attention of the doctor than the patients belonging to the lower middle class or downtrodden people (Waitzkin \& Britt, 1999, p. 2442). Moreover, it is also observed that the patients of lower classes are usually shy and hesitant to get information and in their questioning from their doctor (Tanner, 1984, p. 46; Waitzkin \& Britt, 1999, p. 2442). Therefore, in the whole communication process politeness, care, demonstration of apprehension, and the personal characteristics and features observed by the patients are of great value and worth.

Patients use different languages in medical discourse. In the words of Tanner and Devonish, almost 5000 different languages are being spoken in the whole world (Tanner, 1984. p. 15; Devonish, 2002 p. 1). However, patients scarcely use medical jargons or technical terms in their conversation. Doctors, on the other hand are accustomed to use jargon in medical discourse. Pakistan is a multilingual country with different languages being used for communicative purpose in different areas. Urdu is the national language of Pakistan; a mixture of Persian, Arabian, Sanskrit and Turkish languages. Along with Urdu, people tend to speak regional languages like Punjabi, Saraiki, Sindhi and Balochi [local] languages. Most of the patients who visit government hospitals lack English communication skills. However, doctors who belong to the highly literate community use refine form of language often a mixture of English and Urdu languages. When they come in to contact with patients who normally belong to lower or illiterate class, they cannot build proper communication. This communication gap causes irritancy for doctors, and as a result the frequent interruption makes doctors impolite and irritated.

\section{Methods}

This ethnographic study is based on exploratory research design. In addition, mixed method approach was used to collect, analyze and interpret the data. The mixed method approach is the blend of qualitative and quantitative research data. Observation was used to collect qualitative data whereas questionnaire was used to gather quantitative data. The conversational data of this study were collected from audio recordings gathered from the medical consultation held between doctors and patients. The role of the researchers at this phase was purely of complete observers. Quantitative data were collected through administering a self report questionnaire (SRQ). The population parameter was doctors, patients and to some extent the attendants of the patients from different 
government hospitals. A well planned and convenient sampling technique was used; and 5 doctors and 10 patients were selected for the recording of their conversation in order to collect data. The doctors belonged to the pediatric, gynecology, and surgery departments. In total, 10 audio recordings were gathered from 30 agreeable participants including doctors and patients, straddling the total time duration of 3 hours 15 minutes 30 seconds. The main motivation behind the selection of this research tool was obviously authenticity. Therefore, researchers preferred audio recording of the doctor and patient communication with the help of a tiny audio recorder.

Data collected from questionnaire was analyzed quantitatively. On the other hand, the data collected from observational recording was analyzed qualitatively. Twenty different types of questions were asked in order to explore the four different aspects of doctor-patient interface, specifically information prerequisite (04 types of questions), the doctor's proficiency in communication (09 questions) time of consultation (01 question) and the belief and confidence of patient in his doctor (06 questions). Only one question was used to explore the devoted intention of the patient, the instant result of the meeting with the doctor. To measure the outcomes of the patients' responses, coding scores 1-5 were allocated, such as advanced scores specified more optimistic responses. Therefore, for favorably encouraging worded substances, the coding was used as: strongly agree $=5$; agree $=4$; uncertain $=3$; disagree $=2$; strongly disagree $=1$. Whereas for unfavorably discouraging worded substances, the coding was used: strongly agree $=1$; agree $=2$; uncertain $=3$; disagree $=4$; strongly disagree $=5$. Questionnaire was piloted before administration to ensure its validity and reliability.

The current study had some limitations too. Respondents were selected on convenient sampling technique as it was difficult to use randomization technique on doctors and patients. Furthermore, questionnaire items were translated in local languages to provide complete understanding for the patients. Due to hectic schedule of doctors, some of them declined to help in data collection process. Additionally, some illiterate patients also refused to cooperate in between the survey. Researchers tackled these issues by adding more doctors and more patients in sampling framework in order to determine the complete sample size that was planned for the study.

\section{Data Analysis}

The questionnaire was developed and administered among patients to determine the satisfaction level of patients during doctor-patient conversation. 40 respondents were selected by using convenient sampling technique during hospital visits and questions were asked from them by using Urdu, Punjabi or Saraiki language. Data have been analyzed through applying descriptive statistics technique by calculating the frequency, percentage and mean score of responses. Questionnaire has been divided into 05 categories and codified as under:

1) $\mathrm{IP}=$ Information Provision by the Doctor;

2) $\mathrm{CT}=$ Consulting Time;

3) $\mathrm{CS}=$ Doctor's Communication Skills;

4) $\mathrm{PC}=$ Patient's Confidence in the Doctor;

5) $\mathrm{CI}=$ Compliance Intent

3.1 Medical Discourse Related to Information Provided by the Doctor (IP)

Table 2. Understanding of patients' disease

\begin{tabular}{lllllllll}
\hline Statement & Patients & F/\% & SA & A & UN & DA & SDA & Mean \\
\hline After meeting with my doctor, I am & Male & Frequency & 6 & 5 & 4 & 2 & 3 & 3.45 \\
able to understand my illness in much & & Percentage & 30 & 25 & 20 & 10 & 15 & \\
better way & \multirow{2}{*}{ Female } & Frequency & 3 & 4 & 8 & 4 & 1 & 3.40 \\
& & Percentage & 15 & 20 & 40 & 20 & 5 & 3.42 \\
& \multirow{2}{*}{ Total } & Frequency & 9 & 9 & 12 & 6 & 4 & 3.42 \\
& & Percentage & 22.5 & 22.5 & 30 & 15 & 10 & \\
\hline
\end{tabular}

Note. Strongly Agree SA; Agree A; Uncertain UN; Disagree DA; Strongly Disagree SDA.

Tabular display shown above describes patients' viewpoint about the understanding of their illness during meeting with doctors. $30 \%$ male and $15 \%$ female patients were strongly agree; $25 \%$ male and $20 \%$ female were agree, whereas $20 \%$ male and $40 \%$ female respondents were uncertain about the statement. $25 \%$ patients opined that their doctor's conversation didn't help them in gaining much knowledge about their disease. Overall mean value of total respondents was 3.42 that indicate that participants overall opinion illustrate that they were slightly agree with this statement. 
Table 3. Provision of information about physical condition

\begin{tabular}{lllllllll}
\hline Statement & Patients & F/\% & SA & A & UN & DA & SDA & Mean \\
\hline The doctor provides me all & Male & Frequency & 3 & 1 & 6 & 3 & 7 & 2.50 \\
information which I was & & Percentage & 15 & 5 & 30 & 15 & 35 & \\
anticipating about my physical & Female & Frequency & 5 & 7 & 3 & 2 & 3 & 3.20 \\
condition. & & Percentage & 25 & 35 & 15 & 10 & 15 & \\
& \multirow{2}{*}{ Total } & Frequency & 8 & 8 & 9 & 5 & 10 & 2.85 \\
& & Percentage & 20 & 20 & 22.5 & 12.5 & 25 & \\
\hline
\end{tabular}

Note. Strongly Agree SA; Agree A; Uncertain UN; Disagree DA; Strongly Disagree SDA.

It is the quality of good doctors to make their patients aware about their existing physical health. Table 3 recorded patient's opinion about the conversation of their doctors related to their existing physical health. Data show that majority of the respondents were not informed well about their physical conditions. It is however different among male and female patients. Female patients were found slightly agree that their doctors informed them about their present physical health but male patients were almost disagree with this practice. On the whole mean value was measured 2.85, that signifies patients' responses fall between the categories of uncertain and disagree. It demonstrates that doctors failed to provide valid and complete information regarding patients' health.

Table 4. Inability to comprehend doctor's directions

\begin{tabular}{lllllllll}
\hline Statement & Patients & F/\% & SA & A & UN & DA & SDA & Mean \\
\hline I was unable to comprehend & Male & Frequency & 1 & 3 & 3 & 4 & 9 & 2.15 \\
what did the doctor wanted to & & Percentage & 5 & 15 & 15 & 20 & 45 & \\
ask from me to act. & \multirow{2}{*}{ Female } & Frequency & 3 & 2 & 4 & 7 & 4 & 2.65 \\
& & Percentage & 15 & 10 & 20 & 35 & 20 & \\
& \multirow{2}{*}{ Total } & Frequency & 4 & 5 & 7 & 11 & 13 & 2.40 \\
& & Percentage & 10 & 12.5 & 17.5 & 27.5 & 32.5 & \\
\hline
\end{tabular}

Note. Strongly Agree SA; Agree A; Uncertain UN; Disagree DA; Strongly Disagree SDA.

It becomes sometimes difficult for patients to understand doctors' cues and directions about kinesthetic movements during consultation. Data discussed above show patients' responses about an inverted statement. $65 \%$ male and $55 \%$ female patients were found disagree with this inverted statement. It means that majority of the patients understood doctors' commands well. They understood and acted according to doctors' directions well. It states the ideology and power in the doctors' command, and reflects allegiance and acquiescence in the patients' reactions. The overall mean value was calculated as 2.40 that strengthen the argument discussed earlier.

Table 5. Instructions about looking after myself

\begin{tabular}{lllllllll}
\hline Statement & Patients & F/\% & SA & A & UN & DA & SDA & Mean \\
\hline The doctor advised me clearly to & Male & Frequency & 3 & 5 & 1 & 10 & 1 & 2.95 \\
look after myself regarding the & & Percentage & 15 & 25 & 5 & 50 & 5 & \\
present condition of mine. & \multirow{2}{*}{ Female } & Frequency & 2 & 4 & 6 & 3 & 5 & 2.75 \\
& & Percentage & 10 & 20 & 30 & 15 & 25 & \\
& \multirow{2}{*}{ Total } & Frequency & 5 & 9 & 7 & 13 & 6 & 2.85 \\
& & Percentage & 12.5 & 22.5 & 17.5 & 32.5 & 15 & \\
\hline
\end{tabular}

Note. Strongly Agree SA; Agree A; Uncertain UN; Disagree DA; Strongly Disagree SDA.

In effective and successful medical discourse, doctors normally advise their patients to adopt some precautionary measures. The findings revealed that both male and female respondents collectively gave similar responses. The mean score of male respondents was 2.95 , mean score of female respondents was 2.75 and overall mean responses was 2.85. It demonstrates that a vast majority of the respondents were found disagree with the statement that doctor advised them to look after themselves regarding their sickness and health issues. 


\subsection{Medical Discourse Related to Consulting Time (CT)}

Table 6. Time allocation of consultation

\begin{tabular}{lllllllll}
\hline Statement & Patients & F/\% & SA & A & UN & DA & SDA & Mean \\
\hline I spend much of my time with & Male & Frequency & 0 & 2 & 1 & 14 & 3 & 2.1 \\
the doctor. & & Percentage & 0 & 10 & 5 & 70 & 15 & \\
& \multirow{4}{*}{ Female } & Frequency & 2 & 4 & 2 & 9 & 3 & 2.65 \\
& \multirow{2}{*}{ Total } & Percentage & 10 & 20 & 10 & 45 & 15 & \\
& & Frequency & 2 & 6 & 3 & 23 & 6 & 2.37 \\
& & Percentage & 5 & 15 & 7.5 & 57.5 & 15 & \\
\hline
\end{tabular}

Note. Strongly Agree SA; Agree A; Uncertain UN; Disagree DA; Strongly Disagree SDA.

It was obvious from the previous data that doctors do not give appropriate or suitable time to their patients in government hospitals. The Table 6 describes patient's opinions about the time given to them for diagnosis at hospital. Data show that $85 \%$ respondents were disagree with the statement that their doctors gave them appropriate time for discussion of their disease. However, female patients were given more time and attention as $30 \%$ of them were agree and strongly agree with the statement. Overall mean calculation was found 2.37 . It explains that majority of the respondents were not satisfied with the discussion time given to them by their doctors.

Table 7. Contentment related to conversation time

\begin{tabular}{lllllllll}
\hline Statement & Patients & F/\% & SA & A & UN & DA & SDA & Mean \\
\hline During talk time with my & Male & Frequency & 3 & 2 & 4 & 2 & 9 & 2.40 \\
doctor, I am fully contented & & Percentage & 15 & 10 & 20 & 10 & 45 & \\
with the interface amid me & \multirow{2}{*}{ Female } & Frequency & 4 & 6 & 1 & 8 & 1 & 3.2 \\
and my doctor. & & Percentage & 20 & 30 & 5 & 40 & 5 & \\
& \multirow{2}{*}{ Total } & Frequency & 7 & 8 & 5 & 10 & 10 & 2.8 \\
& & Percentage & 17.5 & 20 & 12.5 & 25 & 25 & \\
\hline
\end{tabular}

Note. Strongly Agree SA; Agree A; Uncertain UN; Disagree DA; Strongly Disagree SDA.

The table shown above describes patients' level of contentment with discussion time and interface between doctor and them. Data show that majority of the male patients were disagree with this argument. However, $50 \%$ female patients were agreed and contended with their discussions and conversation done with their doctors. On the whole $37.5 \%$ patients opined as agree and 50\% patients opined as disagree with the viewpoint. This diversified calculation indicates that some doctors got success in satisfying their patients through their conversation while other doctors failed in doing so.

\subsection{Medical Discourse Related to Doctor's Communication Skills (CS)}

Table 8. Communication regarding disease diagnosis

\begin{tabular}{lllllllll}
\hline Statement & Patients & F/\% & SA & A & UN & DA & SDA & Mean \\
\hline The doctor explained the causes & Male & Frequency & 1 & 3 & 2 & 11 & 3 & 2.4 \\
of my illness in an excellent & & Percentage & 5 & 15 & 10 & 55 & 15 & \\
way. & \multirow{2}{*}{ Female } & Frequency & 0 & 2 & 4 & 8 & 6 & 2.1 \\
& & Percentage & 0 & 10 & 20 & 40 & 30 & \\
& \multirow{2}{*}{ Total } & Frequency & 1 & 5 & 6 & 19 & 9 & 2.25 \\
& & Percentage & 2.5 & 12.5 & 15 & 47.5 & 22.5 & \\
\hline
\end{tabular}

Note. Strongly Agree SA; Agree A; Uncertain UN; Disagree DA; Strongly Disagree SDA.

The data described in above table illustrate that a vast majority of patients rated doctor's style of disease explanation very poor and pathetic. $70 \%$ male and female respondents disagreed with the statement that their doctor explained the causes of their illness in excellent way. Only small number of patients told that their doctors gave disease related explanations in better way. Overall mean value of total sample was 2.25 . 
Table 9. Freedom of discussion and enquiry

\begin{tabular}{lllllllll}
\hline Statement & Patients & F/\% & SA & A & UN & DA & SDA & Mean \\
\hline The doctor provided me an & Male & Frequency & 3 & 4 & 1 & 7 & 5 & 2.65 \\
option to tell or enquire each & & Percentage & 15 & 20 & 5 & 35 & 25 & \\
and every thing I wished to & \multirow{2}{*}{ Female } & Frequency & 6 & 6 & 3 & 5 & 0 & 3.65 \\
know. & & Percentage & 30 & 30 & 15 & 25 & 0 & \\
& \multirow{2}{*}{ Total } & Frequency & 9 & 10 & 4 & 12 & 5 & 3.15 \\
& & Percentage & 22.5 & 25 & 6 & 30 & 12.5 & \\
\hline
\end{tabular}

Note. Strongly Agree SA; Agree A; Uncertain UN; Disagree DA; Strongly Disagree SDA.

Data show that $15 \%$ male and $30 \%$ female patients were strongly agree with the opinion that doctors gave them freedom to discuss or enquire anything during their visit to them. Similarly, $20 \%$ male and $30 \%$ female respondents were found agree with the opinion. However, a large number of patients i.e. $60 \%$ males and $25 \%$ females were disagree with the statement. The mean score of male responses was 2.65 , mean score of female responses was 3.65 and overall mean response was 3.15. Data show difference of experiences between male and female patients. Female patients observed more freedom of conversation than freedom observed by male patients.

Table 10. Empathy skills by treating patient as humans

\begin{tabular}{lllllllll}
\hline Statement & Patients & F/\% & SA & A & UN & DA & SDA & Mean \\
\hline The doctor appeared to be & Male & Frequency & 0 & 3 & 6 & 4 & 7 & 2.25 \\
concerned about me as a & & Percentage & 0 & 15 & 30 & 20 & 35 & \\
human being and not only & Female & Frequency & 1 & 6 & 3 & 6 & 4 & 2.70 \\
about my sickness. & & Percentage & 5 & 30 & 15 & 30 & 20 & 11 \\
& \multirow{2}{*}{ Total } & Frequency & 1 & 9 & 9 & 10 & 2.48 \\
& & Percentage & 2.5 & 22.5 & 22.5 & 25 & 27.5 & \\
\hline
\end{tabular}

Note. Strongly Agree SA; Agree A; Uncertain UN; Disagree DA; Strongly Disagree SDA.

At government hospitals in Pakistan patients are not normally treated as human beings. They are rather related as subjects or sick figures to be tackled mechanically despite humanly. The data shown in above table confirm this viewpoint as majority of the male and female patients opined that their doctors did not treat them as human beings in the conversations made to them. Only $35 \%$ females rated that their doctors showed empathy towards them. Overall mean value of female patients' responses was slightly higher than mean value of male's responses. The overall mean value was 2.48 as above $50 \%$ respondents disagreed with the statement. A large number of patients $22.5 \%$ remained uncertain about this notion.

Table 11. Friendly greetings

\begin{tabular}{lllllllll}
\hline Statement & Patients & F/\% & SA & A & UN & DA & SDA & Mean \\
\hline The doctor welcomed me & Male & Frequency & 0 & 1 & 0 & 8 & 11 & 1.55 \\
prior to address my & & Percentage & 0 & 5 & 0 & 40 & 55 & \\
complaints. & \multirow{2}{*}{ Female } & Frequency & 1 & 3 & 3 & 9 & 5 & 2.45 \\
& & Percentage & 5 & 15 & 15 & 45 & 25 & \multirow{2}{*}{ (Total } \\
& & Frequency & 1 & 4 & 3 & 17 & 16 & \\
& & Percentage & 2.5 & 6 & 7.5 & 42.5 & 40 & \\
\hline
\end{tabular}

Note. Strongly Agree SA; Agree A; Uncertain UN; Disagree DA; Strongly Disagree SDA.

Data shown in above table exhibit the greeting behavior of doctors during patients visit at government hospitals. Only $05 \%$ male respondents were agreed and $95 \%$ respondents were disagreeing with the statement. On the other hand, $20 \%$ female respondents were agreeing and $70 \%$ of them were disagreeing with the same viewpoint. Overall $82.5 \%$ patients were found disagree and strongly disagree that their doctors welcomed them before addressing their complaints. It elucidates the unfriendly and non-professional communicative attitude of doctors at govt. hospitals. Overall mean value of male responses was 1.55 ; mean value of females' responses was 2.45; whereas overall mean value of total sample was 2 . 
Table 12. Using colloquial language

\begin{tabular}{lllllllll}
\hline Statement & Patients & F/\% & SA & A & UN & DA & SDA & Mean \\
\hline Not a single word was & Male & Frequency & 2 & 4 & 1 & 11 & 2 & 2.65 \\
spoken by the doctor that I & & Percentage & 10 & 20 & 5 & 55 & 10 & \\
was unable to understand. & \multirow{2}{*}{ Female } & Frequency & 2 & 2 & 0 & 9 & 7 & 2.15 \\
& & Percentage & 10 & 10 & 0 & 45 & 35 & \\
& \multirow{2}{*}{ Total } & Frequency & 4 & 6 & 1 & 20 & 9 & 2.40 \\
& & Percentage & 6 & 15 & 2.5 & 50 & 22.5 & \\
\hline
\end{tabular}

Note. Strongly Agree SA; Agree A; Uncertain UN; Disagree DA; Strongly Disagree SDA.

The table shown above enlightens the results obtained from an inverted statement asked from patients. $65 \%$ male respondents and $80 \%$ female respondents were found disagree with the statement. It means that doctors often used colloquial language or medical jargons in their conversation that was incomprehensible for the patients. Consciously or unconsciously jargons were used by the doctors and it again shows the hegemony and power of the concerned stakeholders. The overall mean score of male patients was 2.65 , mean value of female patients was 2.15 and overall mean value was 2.40. Data show that majority of the respondents were almost disagree with the statement.

Table 13. Neglecting patients' concerns

\begin{tabular}{lllllllll}
\hline Statement & Patients & F/\% & SA & A & UN & DA & SDA & Mean \\
\hline The doctor overlooked some & Male & Frequency & 6 & 5 & 8 & 1 & 0 & 3.8 \\
of my complaints and & & Percentage & 30 & 25 & 40 & 5 & 0 & \\
problems which I discussed. & \multirow{2}{*}{ Female } & Frequency & 4 & 3 & 6 & 4 & 3 & 3.05 \\
& & Percentage & 20 & 15 & 30 & 20 & 15 & \\
& \multirow{2}{*}{ Total } & Frequency & 10 & 8 & 14 & 5 & 3 & 3.43 \\
& & Percentage & 25 & 20 & 35 & 12.5 & 7.5 & \\
\hline
\end{tabular}

Note. Strongly Agree SA; Agree A; Uncertain UN; Disagree DA; Strongly Disagree SDA.

Giving concern and care to other's point of view is a quality of good and effective discourse. However, in medical discourse, patients often complain that doctors don't pay heed to complaints or doubts raised by them. $30 \%$ males and $20 \%$ females were strongly agree, and $25 \%$ males and $15 \%$ females were found agree with the statement that doctors overlooked their complaints and problems that they tried to discuss. Only $5 \%$ males and 35.5 females were disagreed with the statement.

Table 14. Doctor's inhospitable attitude

\begin{tabular}{lllllllll}
\hline Statement & Patients & F/ \% & SA & A & UN & DA & SDA & Mean \\
\hline The doctor was in & Male & Frequency & 3 & 9 & 5 & 2 & 1 & 3.55 \\
hospitable to me. & & Percentage & 15 & 45 & 25 & 10 & 5 & \\
& Female & Frequency & 2 & 7 & 4 & 5 & 2 & 3.10 \\
& & Percentage & 10 & 35 & 20 & 25 & 10 & \\
& \multirow{2}{*}{ Total } & Frequency & 5 & 16 & 9 & 7 & 3 & 3.33 \\
& & Percentage & 12.5 & 40 & 22.5 & 17.5 & 7.5 & \\
\hline
\end{tabular}

Note. Strongly Agree SA; Agree A; Uncertain UN; Disagree DA; Strongly Disagree SDA.

Giving concern and care to other's point of view is a quality of good and effective discourse. However, in medical discourse, patients often complain that doctors do not pay heed to complaints or doubts raised by them. $30 \%$ males and $20 \%$ females were strongly agree, and $25 \%$ males and $15 \%$ females were found agree with the statement that doctors overlooked their complaints and problems that they discussed. Only 5\% males and 355 females were disagreed with the statement. The overall mean value was calculated 3.43 that signify that overall responses fall in the category of being agree with the statement. It is concluded that doctors are habitual to ignore patients' complaints and problems in government hospitals. 
Table 15. Tolerance and compassionate behavior

\begin{tabular}{lllllllll}
\hline Statement & Patients & F/\% & SA & A & UN & DA & SDA & Mean \\
\hline The doctor paid attention & Male & Frequency & 2 & 2 & 1 & 8 & 7 & 2.2 \\
tolerantly to me and my & & Percentage & 10 & 10 & 5 & 40 & 35 & \\
problems. & Female & Frequency & 1 & 5 & 2 & 7 & 5 & 2.5 \\
& & Percentage & 5 & 25 & 10 & 35 & 25 & 12 \\
& \multirow{2}{*}{ Total } & Frequency & 3 & 7 & 3 & 15 & 2.35 \\
& & Percentage & 7.5 & 17.5 & 7.5 & 37.5 & 30 & \\
\hline
\end{tabular}

Note. Strongly Agree SA; Agree A; Uncertain UN; Disagree DA; Strongly Disagree SDA.

Positive and hospitable attitude of doctor is very important for patients' health and recovery. The above table illustrates the factors of doctors' hospitality in their conversation with patients. Data show that $60 \%$ male patients and $45 \%$ female patients related their doctor as inhospitable during their talks made with them. Only $15 \%$ male and $35 \%$ female patients rejected the statement. A large number of $22.5 \%$ respondents remained uncertain regarding this phenomenon. The overall mean value remained 3.33 that depict the opinions tilted towards agreeableness. Nearly one fourth of the total sample remained uncertain towards this opinion. The ultimate reason can be the silence of patients due to respect for the medical profession.

4.4 Medical Discourse Related to Patient's Confidence in Doctor (PC)

Table 16. Patient's relaxation after consultation

\begin{tabular}{|c|c|c|c|c|c|c|c|c|}
\hline Statement & Patients & $\mathrm{F} / \%$ & SA & A & UN & DA & SDA & Mean \\
\hline \multirow{6}{*}{$\begin{array}{l}\text { I felt relaxed after talking } \\
\text { to my doctor. }\end{array}$} & Male & Frequency & 4 & 9 & 3 & 2 & 2 & 3.55 \\
\hline & & Percentage & 20 & 45 & 15 & 10 & 10 & \\
\hline & Female & Frequency & 5 & 8 & 2 & 2 & 3 & 3.5 \\
\hline & & Percentage & 25 & 40 & 10 & 10 & 15 & \\
\hline & Total & Frequency & 9 & 17 & 5 & 4 & 5 & 3.53 \\
\hline & & Percentage & 22.5 & 42.5 & 12.5 & 6 & 12.5 & \\
\hline
\end{tabular}

Note. Strongly Agree SA; Agree A; Uncertain UN; Disagree DA; Strongly Disagree SDA.

The study also intends to measure patients' confidence in doctors' talks. The data shown in above table describe relaxation level of patients after their consultation visit. It is evident from the results that a large number of patients were relaxed and felt confidence in their doctor's talks. The social status of patients actually made them feel so. They confronted and felt many linguistic and behavioral problems from doctors; still they rated satisfactory level of relaxation related to whole procedure. The overall mean value of all respondents was 3.53.

Table 17. Trust in the diagnosis of patient's disease

\begin{tabular}{|c|c|c|c|c|c|c|c|c|}
\hline Statement & Patients & $\mathrm{F} / \%$ & SA & A & UN & $\mathrm{DA}$ & SDA & Mean \\
\hline \multirow{6}{*}{$\begin{array}{l}\text { The doctor appeared to } \\
\text { be acquainted with what } \\
\text { should be done for my } \\
\text { trouble. }\end{array}$} & Male & Frequency & 6 & 9 & 1 & 3 & 1 & 4.56 \\
\hline & & Percentage & 30 & 45 & 5 & 15 & 5 & \\
\hline & Female & Frequency & 5 & 8 & 3 & 0 & 4 & 3.50 \\
\hline & & Percentage & 25 & 40 & 15 & 0 & 20 & \\
\hline & Total & Frequency & 11 & 17 & 4 & 3 & 5 & 4.03 \\
\hline & & Percentage & 27.5 & 42.5 & 6 & 7.5 & 12.5 & \\
\hline
\end{tabular}

Note. Strongly Agree SA; Agree A; Uncertain UN; Disagree DA; Strongly Disagree SDA.

Above table shows patients' responses towards their trust level in the diagnosis ability of doctors. Here again, $75 \%$ males and $65 \%$ females observed that their doctors were acquainted to sort out their medical issues. However, $20 \%$ female patients were strongly disagree with this statement. The overall mean calculated as 4.03 that explicates the higher level of agreeableness. They showed their trust in the diagnosis abilities of their doctors. Data also express that trust level was higher in male patients than trust of female patients. The mean value of males' responses was 4.56 whereas the mean value of females' responses was 3.50 . 
Table 18. Consideration towards confidentiality

\begin{tabular}{llllllll}
\hline Statement & Patients & F/\% & SA & A & UN & DA & SDA \\
\hline The doctor showed too & Male & Frequency & 4 & 7 & 2 & 5 & 2 \\
much consideration to my & & Percentage & 20 & 35 & 10 & 25 & 10 \\
confidentiality. & Female & Frequency & 6 & 7 & 3 & 1 & 3 \\
& & Percentage & 30 & 35 & 15 & 5 & 15 \\
& Total & Frequency & 10 & 14 & 5 & 6 & 5 \\
& & Percentage & 25 & 35 & 12.5 & 15 & 12.5 \\
\hline
\end{tabular}

Note. Strongly Agree SA; Agree A; Uncertain UN; Disagree DA; Strongly Disagree SDA.

Doctors should keep their patients' secrets confidential as it is the part of their professional code of conduct. Data shown in above table describe consideration level of doctors to observe patients' confidentiality. $20 \%$ males and $30 \%$ females were strongly agree with this statement. 35\% males and same number females were agree with the statement. A significant number of respondents remained uncertain too. On the other side, $35 \%$ males and $20 \%$ females remained disagree with this statement. On the whole, the mean score of total sample was calculated as 3.45; which shows that overall responses are tilted towards agreeableness.

Table 19. Inability of doctor to clear doubts

\begin{tabular}{llllllll}
\hline Statement & Patients & F/\% & SA & A & UN & DA & SDA \\
\hline The doctor was unable to & Male & Frequency & 8 & 7 & 0 & 2 & 3 \\
alleviate my suspicions about & & Percentage & 40 & 35 & 0 & 10 & 15 \\
my poor health. & Female & Frequency & 6 & 11 & 3 & 0 & 0 \\
& & Percentage & 30 & 55 & 15 & 0 & 0 \\
& Total & Frequency & 14 & 18 & 3 & 2 & 3 \\
& & Percentage & 35 & 45 & 12.5 & 5 & 7.5 \\
\hline
\end{tabular}

Note. Strongly Agree SA; Agree A; Uncertain UN; Disagree DA; Strongly Disagree SDA.

Many patients are much concerned about their sickness and poor health and they expect that their doctors will help them to alleviate their doubts. The data show that majority of the respondents recorded their mistrust upon doctors that they could not clear their doubts efficiently. The result deviated from the previous trust related statement where majority of the patients showed trust in their diagnosis and medication ability. Data revealed that doctors didn't help them to remove their superstitions or doubts related to their poor health. The mean score of males was 3.75 , mean value of females was 4.15 , whereas overall mean value was 3.95 . The overall results reached to the level of agreeableness.

\subsection{Medical Discourse Related to Patient's Compliance Intents (CI)}

Table 20. Determination to follow doctor's advice

\begin{tabular}{lllllllll}
\hline Statement & Patients & F/\% & SA & A & UN & DA & SDA & Mean \\
\hline I was determined to act upon & Male & Frequency & 6 & 9 & 2 & 1 & 2 & 3.95 \\
the instructions of my doctor & & Percentage & 30 & 45 & 10 & 5 & 10 & \\
advice. & Female & Frequency & 8 & 7 & 3 & 1 & 1 & 4.0 \\
& & Percentage & 40 & 35 & 15 & 5 & 5 & \\
& \multirow{2}{*}{ Total } & Frequency & 14 & 16 & 5 & 2 & 3 & 3.98 \\
& & Percentage & 35 & 40 & 12.5 & 5 & 7.5 & \\
\hline
\end{tabular}

Note. Strongly Agree SA; Agree A; Uncertain UN; Disagree DA; Strongly Disagree SDA.

The last part of the questionnaire was about the follow-up of doctor-patient discourse during patient visit. Majority of the respondents were fully determined to act upon the advice of their doctors. $30 \%$ male respondents and $40 \%$ female respondents were strongly agree; $45 \%$ male respondents and $35 \%$ female respondents were agree; whereas $10 \%$ males and $15 \%$ females remained uncertain about the statement. The overall mean value was calculated 3.98 of the whole sample. Data indicate that $75 \%$ male and female participants were agree with the statement. 
Table 21. Desire of follow-up consultations

\begin{tabular}{lllllllll}
\hline Statement & Patients & F/\% & SA & A & UN & DA & SDA & Mean \\
\hline I am fully satisfied with & Male & Frequency & 1 & 3 & 1 & 10 & 5 & 2.25 \\
doctor's conversation about & & Percentage & 5 & 15 & 5 & 50 & 25 & \\
treatment and wish to meet & Female & Frequency & 2 & 4 & 6 & 5 & 3 & 2.85 \\
same doctor in future. & & Percentage & 10 & 20 & 30 & 25 & 15 & \\
& \multirow{2}{*}{ Total } & Frequency & 3 & 7 & 7 & 15 & 8 & 2.55 \\
& & Percentage & 7.5 & 17.5 & 17.5 & 37.5 & 20 & \\
\hline
\end{tabular}

Note. Strongly Agree SA; Agree A; Uncertain UN; Disagree DA; Strongly Disagree SDA.

When it was asked from the patients if they wish to consult the same doctor again for medication purposes, the results were quite interesting. $75 \%$ male patients and $40 \%$ female patients refused to express their wish to visit the same doctor again. Only $25 \%$ respondents expressed that they are fully satisfied with doctor's conversation and treatment so they wish to visit same doctor in future. $17.5 \%$ respondents remained uncertain regarding this viewpoint. On the other hand, $57.5 \%$ patients opined that they disagree with this statement. The overall mean value was calculated as 2.55 .

\section{Discussion}

The data obtained from observation were analyzed by applying qualitative content analysis technique. For this purpose, after enquiring the requisite consent and approval from both doctors as well as patients, their discourse was recorded and after that it was transcribed.

After the conversational analysis of doctor as well as patient, it was observed that the utmost politeness approach utilized by both the doctors as well as patient is the strategy of bald-on-record form $(45.38 \%)$, which is followed by negative politeness approach $(31.09 \%)$ as well as positive politeness approach $(19.33 \%)$ and the last but not the least approach is the off-record approach $(4.20 \%)$. The most interesting point to be noted is that the patient normally utilized the bald-on-record approach more often than used by the doctor. Some examples are given as under:

\section{Doctor: khansi kitna hoti thi? (Bald-on-record)}

(How long is the duration of your cough?)

Doctor: blood pressure pahly ya sugar di shikayat? (bald-on-record)

(Are you suffering from blood pressure or diabetes?)

When the politeness strategies are employed by the patients, there is not much difference found between the strategies used by the doctors and the patients, they are rather very much similar to each others. The most frequently used strategies by the patients are mainly the bald -on-record strategies $(32,74.42 \%)$ where as the subsequent being off-record approach $(5,11.63 \%)$, chased by the both positive as well as negative strategies, together recording the equivalent frequencies $(3,6.98 \%)$. Alike doctors, all the patients frequently utilize the bald-on-record approach when they interact with their doctors throughout the consultation process. All the patients replied in a petite and concise way when they were responding to the questions asked by their doctors.

In the conversation with the female patients, less in age than their doctor, the lowest level of solidarity had been chosen however mainly the polite manners at their highest level had been employed. As for instance, when a dental surgeon was enquiring from a female patient of twenty-eight years old "kia ap ko kissi medicine se allergy tu nai?" he employed the word 'aap' (You) which shows his sense of respect, genuineness or solidarity. Likewise, the application of addressing expression as "madam, janab, Amma, chacha" (form of 'Mrs.') and use of "aap, tussan, saein" might exhibit politeness. While in conversation with the male patients less in age than their doctors, the condition is contradictory and opposite as compared to the dealings with the female patients as the doctor is much more direct and use the words like 'acha puttar' and "acha eey dassa". All this is noticeably based on the fact that the both speakera belong to the same gender as well as age group and in these circumstances the doctor does not want to create a space amid the patient and himself; both of them indulge in some sort of informal men-talk along with the more earnest behaviors. On the other hand, dealing with the female patients lesser in age than their doctor, equally the solidarity as well as politeness was balanced. Whereas the utterance of the word 'aap' makes the rate of solidarity much higher as a definite source of sincerity, with the application of phrases used to address such as "amma, bibi, masi, (madam)" intensify the rate of politeness.

Along with transcription, some portion of their non-verbal discourse was also noted into the written form in order to differentiate which type of voice feels right to which type of the patient (i.e., older or else younger). The 
most important of all the factors that affect the communicative process of doctor and the patients was the problem of doctors' selection of vocabulary and expressions and proper and most suitable words in order to explain patients' problems. It was found that doctors often used colloquial language or medical jargons in their conversation that was incomprehensible for the patients and they got worried and confused.

Another factor measured to reflect DPR in medical discourse was the doctors' way of information-seeking. The major purpose of medical discourse is exchange of information between the patient and the doctor. The doctors require information about the patient so that they can make an accurate diagnosis and decision about the condition of their patients to treat them in a proper way. Therefore, they have to enquire after the patients about the causes and symptoms so that they can help them in getting recovery. However, the findings reveal that doctors' talk most of the time reflect their dominance, personally alleged power and huge social distance between the two stakeholders. Furthermore, the accent of the doctor may perhaps have an effect on the patient's understanding of communication of the doctor. Findings show that different types of non-verbal sounds uttered by doctors reflect linguistic and social disparities. Linguistic disparity in vocalization patterns may possibly affect understanding pattern of majority of patients.

Data collected by the patients after their meeting with their doctors show that the patients after their confrontation with their doctor were not fully satisfied. They expected more illustrations, more time, and more devotion on the part of their doctor. Moreover, it is also concluded after considering the interface of patients with their doctors that a large number of the patients complained that they were not informed about their physical condition completely. But the views of male and female patients regarding this matter were totally different. Female patients were slightly agree that their doctors informed them about their present physical health but male patients were almost disagree with this practice.

The overall views conclude that doctors failed to provide valid and complete information regarding patients' health. The other problem faced by the patients was that their doctors did not give a proper and comprehensive explanation of their diseases. It was also evident that male patients were much offended with the attitude and communication of their doctor than female patients. Language barriers caused many difficulties when patients interact with their doctors. The tolerance and indulgence exhibited on the part of the doctor for the patients is an additional factor which affects DPD badly. The doctor's compassion, empathy and reverence towards the patient may have a considerable influence over the communicative process of doctor and patient. The results also signify that communication throughout the medical discourse is mainly doctor-centered. The DPR level in doctor patient discourse was found relatively high, unjustified and substantially unfair. The study concludes with strong recommendation to incorporate legal and moral code in health department. It is further suggested to arrange communication trainings for doctors to provide them trainings on politeness strategies, behavioral issues and communication skills. Last but not least, there is dire need to pursue further research in the fields of medical discourse, ESP for doctors, and medical pedagogy.

\section{References}

Brown, P., \& Levinson, S. (1978). Universals in language usage: politeness phenomena. Cambridge: Cambridge University Press.

Brown, P., \& Levinson, S. C. (1987). Politeness: Some Universals in Language Usage (vol. 4). Cambridge: Cambridge University Press. https://doi.org/10.1017/CBO9780511813085

Brown, G., \& Yule, G. (1983). Discourse Analysis. Cambrige: Cambridge University Press. https://doi.org/10.1017/CBO9780511805226

Cassell, E. J., \& Skopek, L. (1977). Language as a Tool in Medicine: Methodology and theoretical framework. Journal of Medical Education, 52(3), 197-203. https://doi.org/10.1097/00001888-197703000-00004

Devonish, H. (2002). Language rights, justice and the Constitution? Part II. The Sunday Gleaner, Kingston, Jamaica, Jan. 20.

Epstein, R. M., Campbell, T. L., Cohen-Cole, S. A., Mc Whinney, I. R., \& Smilkstein, G. (1993). Perspectives on patient-doctor communication. J Fam Pract, 37(4), 377-388.

Frederickson, L. G., \& Peter, E. B. (1995). Evaluation of a patient education leaflet designed to improve communication in medical consultations. Patient Education and Counseling, 25, 51-57. https://doi.org/10.1016/0738-3991(94)00696-J

Hak T., \& Campion, P. (1999). Achieving a patient-centered consultation by giving feedback in its early phases. Postgrad Med J., 75(885), 405-409. https://doi.org/10.1136/pgmj.75.885.405 
Korsch, B. M., \& Vida, F. N. (1972). Doctor-patient communication. Scientific American, 227(2), 66-74. https://doi.org/10.1038/scientificamerican0872-66

Leech, G. (1983). Principles of Pragmatics. London: Longman.

Maynard, D. W. (1991). Interaction and Asymmetry in Clinical Discourse. The American Journal of Sociology, 97(2), 448-495. https://doi.org/10.1086/229785

Parsons, T. (1978). Action Theory and the Human Condition. New York: Free Press.

Simpson, M. R., Buckman, M., Stewart, P., Maguire, M., Lipkin, D., \& Novack, J. (1991). Till. Doctor-patient communication: the Toronto consensus statement. BMJ, 303(6814), 1385-1387. https://doi.org/10.1136/bmj.303.6814.1385

Tanner, B. A. (1984). Language and Communication in General Practice. London: Hodder and Stroughton, 1976.

Waitzkin, H., \& Theron, B. (1989). A Critical Theory of Medical Discourse: How Patient and Health Professionals deal with social problems. International Journal of Health Services, 19(4), 577-597. https://doi.org/10.2190/L84U-N4MQ-9YAC-D4PP

\section{Copyrights}

Copyright for this article is retained by the author, with first publication rights granted to the journal.

This is an open-access article distributed under the terms and conditions of the Creative Commons Attribution license (http://creativecommons.org/licenses/by/4.0/). 